\title{
A dynamic analysis of in-situ stress state at the Upper Tamakoshi Hydroelectric Project area, Nepal
}

\author{
K.K. Panthi and C.B. Basnet
}

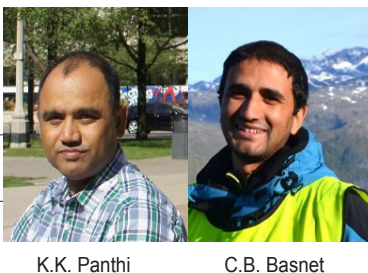

Abstract: The in-situ stress condition in the rock mass is influenced by both tectonic and geological environment, such as faulting and shearing in the rock mass. This influence is of considerable magnitude in the Himalayan region where the tectonic movement is active,resulting periodic dynamic earthquakes. Each large-scale earthquake causes both accumulation and sudden release of strain energy instigating changes in the in-situ stress environment in the rock mass. This paper evaluates the influence of local shear fault on the in-situ stress state along the shotcrete lined high pressure tunnel of Upper Tamakoshi Hydroelectric Project, $456 \mathrm{MW}$ in Nepal. A detailed assessment of the in-situ stress state is carried out by using both; measured data and three-dimensional numerical analysis using FLAC3D. The analysis includes evaluation on the possible changes in the in-situ stress state in the rock mass caused by seismic activities (dynamic loading).

Keywords: In-situ stress, 3D numerical model, dynamic loading

\section{Introduction}

Danthi and Basnet (2017) highlighted that one of the design issues in unlined/ shotcrete lined tunnel is the magnitude of minor principal stress. In the Upper Tamakoshi HEP in-situ stresses were initially measured by using 3D overcoring method nearby the bottom of Tamakoshi River valley (SINTEF, 2008). Based on the measured stress state, the location of the headrace tunnel was selected in such a way that the maximum internal water pressure becomes about 4.2 $\mathrm{MPa}$ at the end of the headrace tunnel. This decision was based on the assumption that the tunnel location will have close to similar in-situ stress state as that of the stress measurement location. However, it was found later that the minor principal stress measured by hydraulic fracturing (SINTEF, 2013) at the end of the high pressure headrace tunnel was not found to be sufficient to avoid the potential hydraulic jacking as explained by Broch (1982) and Panthi (2014). As a result, the tunnel alignment was finally shifted to a new location where the unlined/ shotcrete lined part of the tunnel will now experience the maximum pressure of about 1.2 MPa (12 bars). The main aim of this paperis to evaluate the in-situ stress state of the Tamakoshi HEP area with the dynamic loading.

Considering the limitation of $2 \mathrm{D}$ assessment, it is decided to implement the three-dimensional numerical model $\left(\mathrm{FLAC}^{3 \mathrm{D}}\right)$ in order to evaluate the stress state of the Tamakoshi area due to the presence of complex topography. The field measured $3 \mathrm{D}$ in-situ stress data are used to validate the model for tectonic stress magnitude and orientation. While doing so, the large scale discontinuities are also incorporated in the model. In addition, the local shear bands of schistosity as shear zone is also introduced in the model in order to quantify the stress attenuation at the tunnel location. The dynamic (earthquake) analysis has been carried out to evaluate the influence of seismicity on the in-situ stress state of the area.

\section{Upper Tamakoshi hydroelectric project Area} Upper Tamakoshi Hydroelectric Project (UTHEP) is located in Dolakha district of Nepal, which is towards North-East from Kathmandu valley. The project is in under construction phase and has an installed capacity of $456 \mathrm{MW}$ and exploits $66 \mathrm{~m}^{3} / \mathrm{sec}$ design discharge and $822 \mathrm{~m}$ gross head (Reimer and Bock, 2013). The project consists of different structures such as headworks, headrace tunnel, vertical penstock shafts, underground power station, tailrace and access tunnels as shown in Figure 1a and Figure 1b. The pressurized headrace tunnel ends at the top of the penstock shaft and is planned to be shotcrete lined tunnel. Both old and new versions of headrace tunnel alignments are shown in Figure 1 and Figure 2a.

\section{Geology and Tectonics}

Geologically, the project is located in the Higher Himalayan Tectonic Formation of eastern Nepal Himalaya (Panthi and Basnet, 2017). The detailed geological mapping of the project area during the feasibility study concluded that the rock types in the project area are characterized as micaceous schist and banded gneiss with abundant mica contents (Norconsult, 2005). The general trend of the tectonic stress orientation in the Himalayas is NE-SW at the north-western part of the Himalayas and is more or less N-S at the southeastern part of the Himalayas (Panthi, 2012). The trend nearby the project area appears to be in the direction approximately $\mathrm{N} 2 \mathrm{O}-4 \mathrm{O}^{\circ} \mathrm{E}$.

\section{Topography and Weakness Zones}

The headrace tunnel is located along the right bank of Tamakoshi River (Figure 1). The highest elevation of the nearest hill from the tunnel is about 4500 masl and the lowest elevation is at the Tamakoshi River at about 1250 masl. The level difference is about $3300 \mathrm{~m}$ within the horizontal distance of about $5500 \mathrm{~m}$ and the slope of the terrain is 30 to 40 degrees. The slopes and the level differences show that the Tamakoshi River is a deep 
valley and the topography represents a high relief. In addition to the Tamakoshi River, there is Gongar Khola (a signal river) near to the outer reach of the headrace tunnel. The Gongar Khola is also a deep valley connected to the Tamakoshi valley making a confluence at an elevation of about 1250 masl. Both valleys will have to be considered in the stress state analysis for the logical estimation of the stress state of the project area.
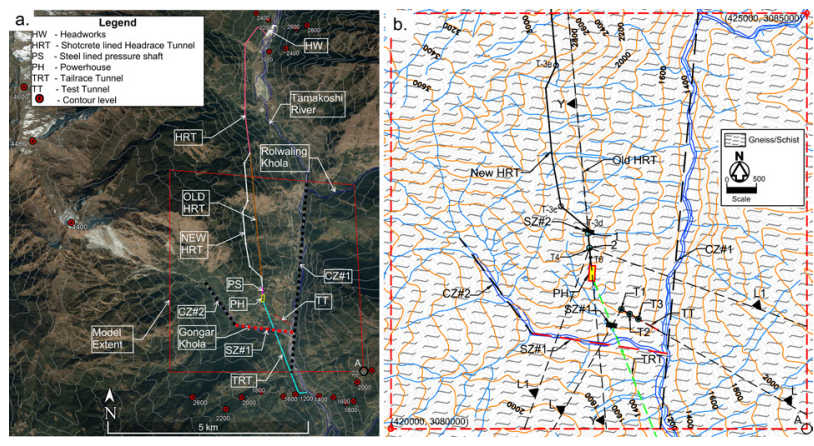

Figure 1. a. 3D topography, major lineaments and layout of Upper Tamakoshi project overlaid in google earth map (Source: https://earth.google.com), b. Topographic map of the project area inside model extent

The Tamakoshi River is inferred with a crushed zone as indicated by CZ\#1 (Figure 1). Similarly, the upper left tributary of the Gongar valley is also inferred as a crushed zone and is denoted as CZ\#2. This zone is orienting away from the foliation of the rock mass and the formation of the zone is assumed by the similar way as that of the CZ\#1. In addition, two more weakness zones were encountered during tunnel excavation in both tailrace tunnel and old headrace tunnel, which were considered as shear zones and are denoted by SZ\#1 and SZ\#2, respectively (Figure $1 \mathrm{~b}$ and Figure 2a). The orientations of these zones are along the foliation of the rock mass. The orientation of all four weakness zones are shown in Figure 2b.
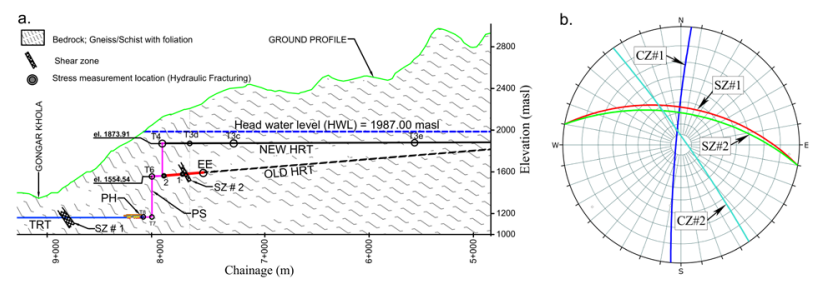

Figure 2. a. Tunnel alignment profile with geology, b. stereographic projection of weakness zones (Lower hemisphere, equal angle)

\begin{tabular}{|c|l|l|l|l|l|l|l|l|l|}
\hline \multirow{2}{*}{ Stresses } & \multicolumn{4}{|c|}{ T1 } & \multicolumn{3}{c|}{ T2 } & \multicolumn{3}{c|}{ T3 } \\
\cline { 2 - 11 } & $\mathrm{MPa}$ & Trend & $\begin{array}{l}\text { Plunge } \\
\text { (deg.) }\end{array}$ & $\mathrm{MPa}$ & Trend & Plunge (deg.) & $\mathrm{MPa}$ & $\begin{array}{l}\text { Trend } \\
\text { (deg.) }\end{array}$ \\
\hline $\mathrm{S} 1$ & $18.4 \pm 2.9$ & $\mathrm{~N} 120.5^{\circ} \mathrm{E}$ & 27.9 & $17.4 \pm 2.2$ & $\mathrm{~N} 204.6^{\circ} \mathrm{E}$ & 30.3 & $21.6 \pm 3.8$ & $\mathrm{~N} 21.1^{\circ} \mathrm{E}$ & 10.4 \\
\hline $\mathrm{S} 2$ & $12.4 \pm 4.7$ & $\mathrm{~N} 239.5^{\circ} \mathrm{E}$ & 42.5 & $10.8 \pm 1.7$ & $\mathrm{~N} 100.2^{\circ} \mathrm{E}$ & 23 & $12.6 \pm 2.8$ & $\mathrm{~N} 116.5^{\circ} \mathrm{E}$ & 27.2 \\
\hline $\mathrm{S} 3$ & $7.1 \pm 1.8$ & $\mathrm{~N} 9.0^{\circ} \mathrm{E}$ & 34.7 & $1.1 \pm 2.7$ & $\mathrm{~N} 339.4^{\circ} \mathrm{E}$ & 50.4 & $6.4 \pm 4.8$ & $\mathrm{~N} 272.2^{\circ} \mathrm{E}$ & 60.6 \\
\hline
\end{tabular}

Table 1. Stress measurement in Test Tunnel by 3D overcoring (SINTEF, 2008)

Note: S1, S2, and S3 are major, intermediate and minor principal stresses respectively.

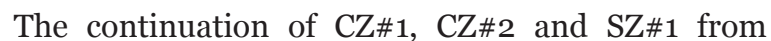
surface is assumed as deep as 800 masl, which gives the lowest depth of about $450 \mathrm{~m}$ from the surface. The width of these zones is taken as half of river width at surface because the width becomes narrower and narrower while going deeper into the rock mass. The width of SZ\#1 at tunnel level also shows the same trend i.e. narrower than the river width at surface. On the other hand, the lowest level of SZ\#2 is effectively taken about $50 \mathrm{~m}$ below the level of Gongar valley. To do so, the lowest elevation of SZ\#2 is fixed at 1600 masl at the location of intersection with CZ\#2 and at 1250 masl with CZ\#1. The hypothesis here is that the confinement increases due to the tectonic stress and the impact of shear zone on the stress state will be insignificant below the level of Gongar valley at SZ\#2 location. The width of SZ\#2 is considered equal to that found at the tunnel during excavation.

\section{Measured Stress at the Project}

In 2008, SINTEF carried out 3D overcoring test at three different locations of the test tunnel near powerhouse to estimate the magnitude and orientation of in-situ stress state (the test locations are shown in Figure 1b), which is situated at the bottom of the valley at an elevation of about 1250 masl. Test results of the in-situ stress state are shown in Table 1.

Later in 2013, minor principal stress was measured by using hydraulic fracturing technique at locations 1 and 2 along old headrace tunnel nearby the SZ\#2 (Figure $1 \mathrm{~b}$ and Figure 2a), which indicated the minor principal stress as given in Table 2.

\begin{tabular}{|l|l|l|l|l|}
\hline \multirow{2}{*}{ Location } & \multicolumn{4}{|l|}{ Minor principal stress (Mpa) } \\
\cline { 2 - 5 } & min. & avg. & max & Sd* \\
\hline 1a & 1.6 & 3.2 & 4.9 & 1.0 \\
\hline 2a & 1.2 & 5.4 & 9.1 & 2.5 \\
\hline \multicolumn{4}{|l}{ aSINTEF(2013), *Standard deviation } \\
\hline
\end{tabular}

Table 2: Stress measurement by hydraulic fracturing

\section{Stress State Analysis}

The stresses measured at particular locations may essentially not be representative of the whole area of interest because of the complex topography and the presence of weakness zones. Therefore, both static and dynamic analyses are carried out for the given extent of model in order to quantify the stress values at the location of interest. In doing so, the numerical modelling 
program i.e. FLAC $^{3}$ D (ITASCA, 2017) is extensively employed. In static analysis, 3D stresses measured at test tunnel are used to validate the model and corresponding minor principal stresses are recorded at the tunnel location. The minor principal stresses from the model are compared with the measured values at tunnel location. In addition, dynamic analysis is carried out on the same model, which statically is already in equilibrium state.

\section{Input Parameters to the Model}

Input parameters required for the model are quantified based on the detail information of Tamakoshi HEP area. Rock mass parameters (Table 3) and interface parameters (Table 4) are most important input variables to be quantified in carrying out the numerical analysis.

\begin{tabular}{|c|c|c|c|}
\hline Parameters & & Unit & Values \\
\hline Density ${ }^{a}, Y$ & & $\mathrm{~kg} / \mathrm{m}^{3}$ & 2745 \\
\hline Poisson's ratioa , । & & & 0.2 \\
\hline Elasticity modulu & $\mathrm{E}_{\mathrm{ci}}$ & Gpa & 30.2 \\
\hline Intact rock stren & a (UCS) & Mpa & 61 \\
\hline Bulk Modulus, $\mathrm{K}$ & & GPa & 16.8 \\
\hline Shear Modulus, ( & & GPa & 12.6 \\
\hline alaboratory test r & It & & \\
\hline
\end{tabular}

Table 3. Mechanical properties of Gneiss / Schist

In Table 4, the rock mass quality of weakness zone is defined by GSI, which is considered as 25 for all four weakness zones. The GSI value is then used to calculate the deformation modulus of the rock mass in the weakness zones, which is denoted by Eo (young's modulus of infilled material). The shear modulus of infilled material (Go) is calculated from Eo and Poisson's ratio of infilled material (vo). The normal and shear stiffnesses (kn and ks, respectively) are calculated by using the relationships given by Rocscience (2017) where $t$ is the thickness of the weakness zone. Usually, the friction angle ranges from 150 to 300 in case of fault / weakness zones (Barton, 1973). Friction angle of $25^{\circ}$ is taken as the most likely value for this case.

\section{Model Geometry and Strategy}

$3 \mathrm{D}$ box of size $5000 \mathrm{~m} \times 5000 \mathrm{~m} \times 5000 \mathrm{~m}$ is created

\begin{tabular}{|c|c|c|c|c|c|c|c|c|c|c|c|}
\hline \multirow{2}{*}{$\begin{array}{l}\text { (Figure } 3 a \text { ), which } \\
\text { in corp or a tes } \\
\text { the topography }\end{array}$} & \multirow{2}{*}{ Interfaces } & $\mathrm{E}_{\mathrm{ci}}$ & $\mathrm{G}_{\mathrm{ci}}$ & \multirow[t]{2}{*}{ GSI } & $\mathrm{E}_{0}$ & \multirow{2}{*}{$\mathrm{v}_{0}$} & $\mathrm{G}_{0}$ & $\mathrm{t}$ & $\mathrm{k}_{\mathrm{n}}$ & $\mathrm{k}_{\mathrm{s}}$ & Friction angle \\
\hline & & $\mathrm{GPa}$ & $\mathrm{GPa}$ & & $\mathrm{GPa}$ & & $\mathrm{GPa}$ & $\mathrm{m}$ & $\mathrm{Pa}$ & $\mathrm{Pa}$ & Deg \\
\hline shown in Figure & $\mathrm{CZ \# 1}$ & 30.2 & 12.6 & 25 & 1.8 & 0.1 & 0.82 & 35 & $5.1 \mathrm{E}+07$ & $2.3 E+07$ & 25 \\
\hline 1. The mass $a b$ & CZ\#2 & 30.2 & 12.6 & 25 & 1.8 & 0.1 & 0.82 & 25 & $7.2 \mathrm{E}+07$ & $3.3 E+07$ & 25 \\
\hline top & SZ\#1 & 30.2 & 12.6 & 25 & 1.8 & 0.1 & 0.82 & 25 & $7.2 \mathrm{E}+07$ & $3.3 \mathrm{E}+07$ & 25 \\
\hline 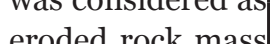 & SZ\#2 & 30.2 & 12.6 & 25 & 1.8 & 0.1 & 0.82 & 30 & $6.0 \mathrm{E}+07$ & $2.7 \mathrm{E}+07$ & 25 \\
\hline
\end{tabular}

body over the

past geologic period and is grouped with separate group name. The whole geometry is meshed with tetrahedron volume mesh of different sizes. First of all, the total stresses including tectonic stress are initialized in each zone for whole box and the model is run for initial state. Once the model converged to the equilibrium within prescribed limit of unbalanced force, the rock mass above the real surface topography is excavated and the interfaces CZ\#1, CZ\#2 and SZ\#1 are created (Figure 3b and Figure $3 \mathrm{c}$ ) and the model is run once again until the second equilibrium state is reached. The model is run for various combinations of tectonic stress magnitudes and directions so that the principal stresses are converged to the measured principal stresses at test tunnel. Once the model is validated, $\mathrm{SZ} \# 2$ is also introduced and the model is again run until it is in equilibrium, in order to quantify the minor principal stress along tunnel alignment. In addition, dynamic analysis is carried out by applying the seismic acceleration as dynamic input at the base of the model and the surface acceleration is tracked in order to match with given peak ground acceleration (PGA).

\section{Static Analysis}

First, static analysis is carried out for different tectonic stress level and orientations so that the output results are comparable with measured stress at respective locations. In doing so, the model is run for all possible combinations of maximum tectonic stress magnitudes of 15,20 and $25 \mathrm{MPa}$, with varying orientation of $\mathrm{N}_{2} \mathrm{O}^{\circ} \mathrm{E}, \mathrm{N}_{3} \mathrm{O}^{\circ} \mathrm{E}$ and $\mathrm{N} 40^{\circ} \mathrm{E}$, and minimum tectonic stress magnitudes of $\mathrm{o}$, 5 and $10 \mathrm{MPa}$. Output of the in-situ stresses form the model are compared with the measured ones at different locations of test tunnel.

After having closer look at both magnitude and orientations of the stresses, the stresses measured at location T2 are found more representative with respect to the modeled stresses. Hence, the location T2 is taken as decisive location where the major principal stresses from the model are comparable in regards with both magnitudes and orientations. The orientation of $\mathrm{S} 1$ for T2 shows that $\mathrm{S} 1$ in case of $20 \mathrm{MPa}$ maximum tectonic stress with $\mathrm{N}_{3} \mathrm{O}^{\circ} \mathrm{E}$ seems very close to the measured orientation but magnitude found was not as close as expected. Considering this in mind, the model is again orientation of $\mathrm{N} 35^{\circ} \mathrm{E}$ and $5 \mathrm{MPa}$ as minimum tectonic stress, which gave satisfactory results (Table 4). run with $20 \mathrm{MPa}$ as maximum tectonic stress with an

\footnotetext{
Table 4: Input parameters for interfaces
} 

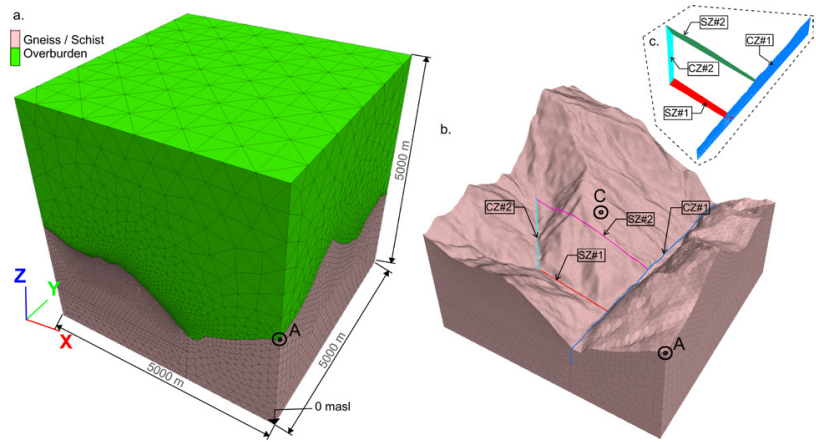

Figure 3. a. 3D geometry with overburden, b. 3D terrain after erosion and c. weakness zones

\section{Dynamic Analysis}

The whole Himalaya region is very dynamic and has been witnessing large number of various scaled earthquakes. The Upper Tamakoshi HEP is relatively close (about $13 \mathrm{~km}$ ) to the epicenter of MW 7.3 aftershock that occurred on 12th of May 2015, as indicated in Figure 4 and discussed by Bhattarai et al. (2015). The attempt here is to simulate the seismic waves generated during this aftershock, which was supposed to have strong impact on the project area.

USGS (2015) computed peak ground acceleration (PGA) in terms of the fraction of $\mathrm{g}$ (acceleration due to gravity) after this event has occurred. The result shows that the value of PGA is about $0.4 \mathrm{~g}$ at the surface location above unlined pressure tunnel (Figure 4).

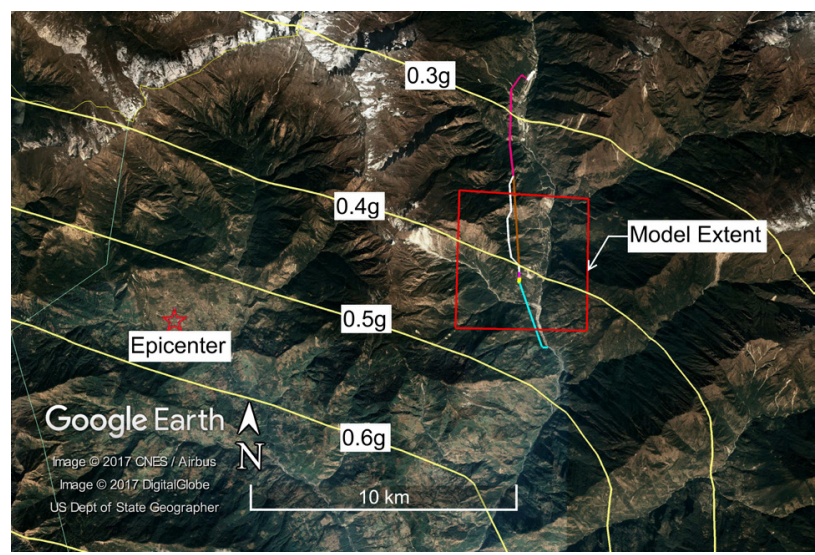

Figure 4. Contours of peak ground acceleration (PGA) as a fraction of $g$ (Source: KMZ file from USGS (2015) overlaid in Google earth map).

According to Bhattarai et al. (2015), the corresponding frequency of seismic wave is about $1 \mathrm{~Hz}$, which is estimated by taking the reference from the seismic wave characteristics measured at different seismological stations in Kathmandu, Nepal. The dynamic loading is applied as a sinusoidal acceleration wave at the base of statically stable $3 \mathrm{D}$ model. The corresponding acceleration is recorded in one of the locations at the surface above unlined tunnel. The input values are changed until the surface acceleration from the model becomes closer to the computed PGA value of about $0.4 \mathrm{~g}$ $\left(4 \mathrm{~m} / \mathrm{s}^{2}\right)$ as indicated in Figure 5 .

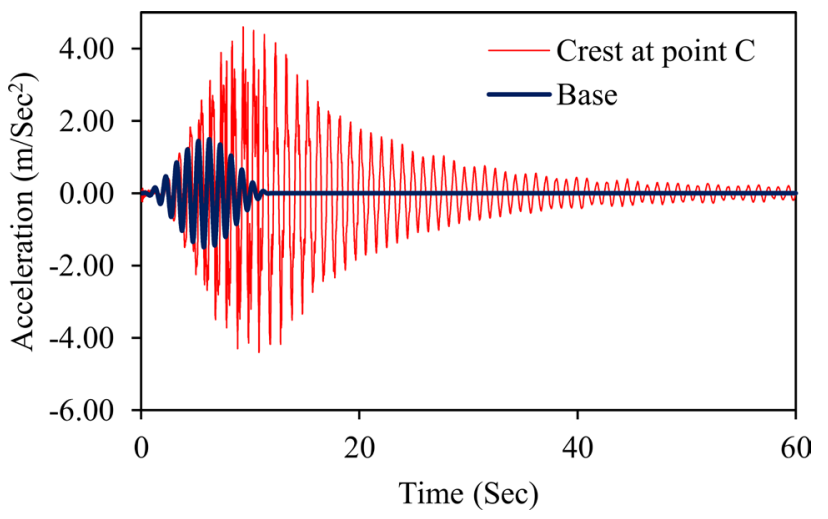

Figure 5. East-West acceleration at base and crest of the given 3D model

\section{Results and discussions}

As expected, the model validation process has indicated that there is significant influence of tectonic stress magnitude and direction in the stress state of Tamakoshi area. The model is validated for maximum horizontal stress of $20 \mathrm{MPa}$ with an orientation of $\mathrm{N} 35^{\circ} \mathrm{E}$. The corresponding minimum horizontal tectonic stress is resulted as $5 \mathrm{MPa}$, which has significant role to generate the intermediate and minor principal stresses at test locations. In addition, the stress state is also influenced by the 3D topography and major geological lineaments present in the area.
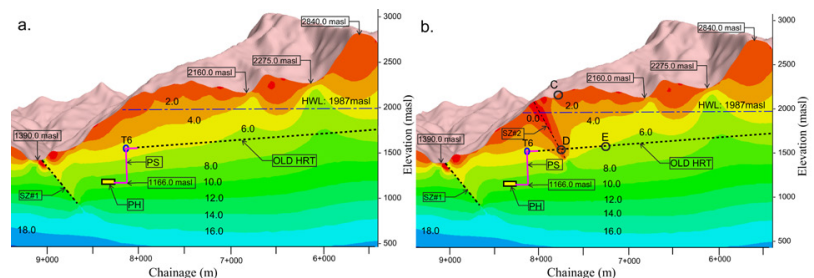

Figure 6. Minor principal stress (MPa) along Old HRT (Y-Y) after static analysis; a. without SZ\#2 and b. with SZ\#2

In order to quantify the stress attenuation due to the presence of shear zone (SZ\#2), minor principal stress from the model is compared between two cases i.e. without SZ\#2 (Figure 6a) and with SZ\#2 (Figure 6b). It is found that minor principal stress is reduced at the location of the SZ\#2 along tunnel alignment as shown in Figure 6 (chainage is in accordance with Figure 2a). The figure also shows that the destressing gradually increases as the elevation of the SZ\#2 goes up. This is due to the fact that at lower elevations, especially below the valley level, confinement from tectonic stress increases rapidly. The opposite is the case at higher elevations because the confinement to SZ\#2 from the Gongar valley side gradually decreases as the elevation increases. 


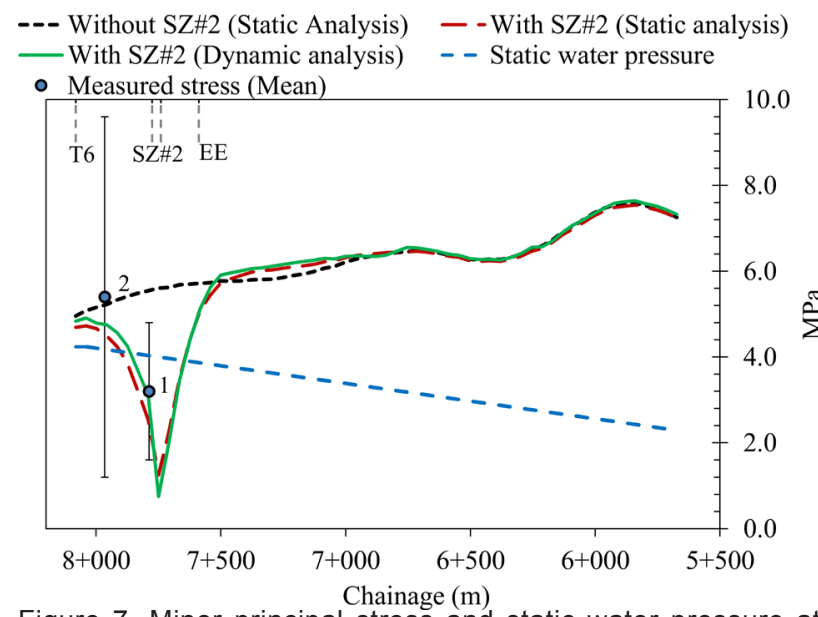

Figure 7. Minor principal stress and static water pressure at tunnel location along Old HRT

Figure 7 shows minor principal stress from static analysis (with and without SZ\#2), minor principal stress from dynamic analysis (with SZ\#2), maximum static water pressure and measured stress at two locations along the tunnel alignment. The minimum value of measured stress at location 1 matches quite well with the model result, which clearly indicates the impact of shear zone on the stress measurement. The figure further shows that it would have been possible to use shotcrete lined pressure tunnel if there was no SZ\#2 since the chance of hydraulic jacking is almost negligible. However, due to the presence of the SZ\#2, there is considerable destressing and the minor principal stress becomes considerably less than the static water pressure at the location of the SZ\#2 indicating higher possibility of hydraulic jacking at this location. Furthermore, the dynamic analysis also shows similar trend of the stress state (at the end of dynamic time period of $60 \mathrm{sec}$ ) as that in static analysis. However, there are some discrepancies in the output at the location of SZ\#2 and nearby area (Figure 7).

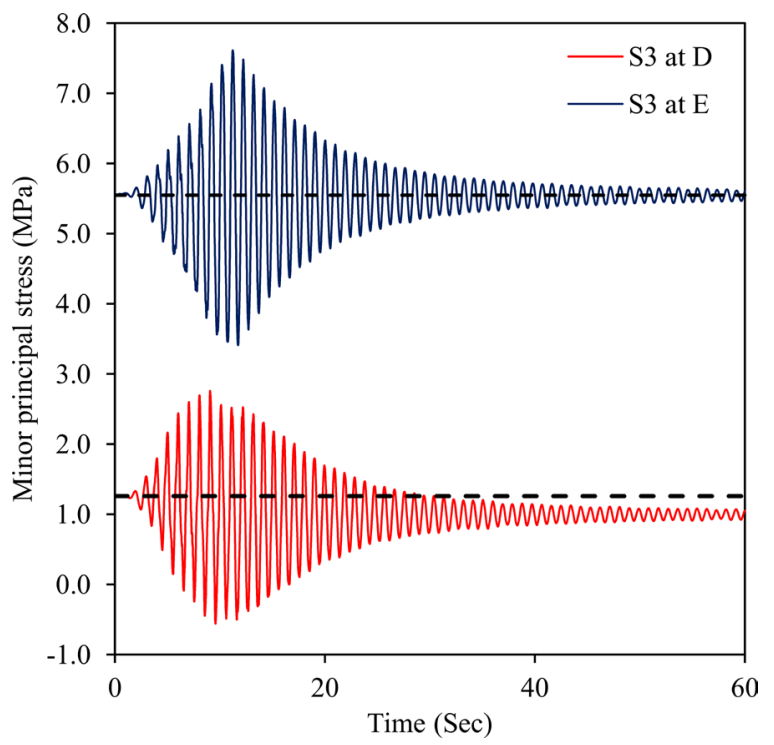

Figure 8. Minor principal stress recorded over the dynamic time period in $3 \mathrm{D}$ model
Figure 8 shows the minor principle stress recorded during the dynamic time period at two different locations; i.e. D and E (Figure 6). The figure shows that there is high fluctuation in the stress values during highest shaking period. The stress value at location E eventually dampens and reaches to its original value, which belongs to the point where intact rock mass exist and is far from SZ\# 2. However, at location D where SZ\#2 is situated, the stress dampens to a new stress value and is reduced from the original value. This indicates that the weakness and fault zones are vulnerable areas during seismic events and permanent change in the stress state are eminent.

\section{Conclusions}

The static analysis of the in-situ stress state suggests that outer reach of Upper Tamakoshi headrace system is influenced by the slope topography of two valleys. Hence, the $3 \mathrm{D}$ topographic effect has considerable impact in the state of in-situ stress and is of major issue while selecting unlined pressure tunnel alignment. In addition, the local shear zone attenuates the stress state significantly. The decision made to change the alignment of the headrace tunnel further at upper level was wise decision. However, it is noted here that the new headrace tunnel alignment needs to be analyzed in detail to assess the vulnerability for the hydraulic jacking and water leakage caused by the presence of shear zones and futures along tunnel alignment. The dynamic seismic simulation shows that there is permanent reduction in the stress state at shear and weakness zones.

Krishna Kanta Panthi, PhD, is an Associate Professor in Department of Geoscience and Petroleum, Norwegian University of Science and Technology (NTNU), Norway, since 20o8. He holds PhD degree in Rock Engineering, MSc in Hydropower Development and MSc in Tunneling. He is the author of many scientific papers published from very renowned journals published internationally. He has more than 20 years of experience in research, design and construction supervision of tunneling, hydropower and slope stability projects.

Corresponding E-mail: krishna.panthi@ntnu.no

Er. Chhatra Bahadur Basnet is conducting his PhD research at the Department of Geoscience and Petroleum,, Norwegian University of Science and Technology (NTNU), Trondheim, Norway. He holds MSc degree in Hydropower Development from NTNU. He has more than six years of working experience in planning, design, and construction supervision of number of hydropower projects in Nepal.

E-mail: chhatra.basnet@gmail.com 


\section{References}

Barton, N., 1973. "A review of the shear strength of filled discontinuities in rock." Fjellspregningsteknikk, Bergmekanikk, Oslo, Tapir Press, Trondheim, pp. 19.1-19.38.

Bhattarai, M., Adhikari, L.B., Gautam, U.P., Laurendeau, A., Labonne, C., Hoste-Colomer, R., Sebe, O. and Hernandez, B., 2015. "Overview of the large 25 April 2015 Gorkha, Nepal, earthquake from accelerometric perspectives." Seismological Research Letters, 86(6), pp.1540-1548.

Broch, E., 1982. "The development of unlined pressure shafts and tunnels in Norway." ISRM International Symposium. International Society for Rock Mechanics.

ITASCA, 2017. FLAC ${ }^{3 \mathrm{D}} 6.0$ User's Mannual.

Norconsult, 2005. "Feasibility study report of Upper Tamakoshi Hydroelectric Project, Nepal.” Nepal Electricity Authority.

Panthi, K., 2012. "Evaluation of rock bursting phenomena in a tunnel in the Himalayas." Bulletin of Engineering Geology and the Environment, 71(4): pp. 761-769

Panthi, K.K., 2014. "Norwegian Design Principle for High Pressure Tunnels and Shafts: It's Applicability in the Himalaya." Hydro Nepal: Journal of Water, Energy and Environment, 14: 36-40.
Panthi, K.K. and Basnet, C.B., 2017. "Design review of the headrace system for the Upper Tamakoshi project, Nepal." The International Journal on Hydropower and Dams, Vol. 24, Issue 1, pp. 60-67.

Reimer, W. and Bock, H., 2013. "Report on the October 2013 project mission, Upper Tamakoshi Hydroelectric Project.” Nepal Electricity Authority, Nepal.

Rocscience, 2017. Rocscience software package and website visited on 13.10.2017:https://www. rocscience.com/help/phase2/webhelp9/theory/ Estimating_Joint_Stiffness.htm.

SINTEF, 2008. "Rock stress measurement at the Upper Tamakoshi Hydroelectric project.” SBF IN Fo8112.

SINTEF, 2013. "Rock stress measurement by hydraulic fracturing at the Upper Tamakoshi Hydroelectric project, Nepal." SBF IN Fo8112.

USGS, 2015. U.S. Geological Survey: ShakeMap of M 7.3 aftershock- 19 km SE of Kodari, Nepal: (https:// earthquake.usgs.gov/earthquakes/eventpage/ us20002ejl\#shake map) 